\title{
Steady State Volume of Distribution
}

National Cancer Institute

\section{Source}

National Cancer Institute. Steady State Volume of Distribution. NCI Thesaurus. Code C85538.

The apparent volume occupied by an exogenous compound during the time point when the plasma concentration of the compound reaches steady state levels. 